\title{
Seismic Response of Fiber-Reinforced Concrete Coupled Walls
}

\author{
by Rémy D. Lequesne, Gustavo J. Parra-Montesinos, and James K. Wight
}

The behavior of coupled T-shaped structural walls was studied through tests of two large-scale four-story specimens under reversed cyclic lateral displacements. The use of tensile strainhardening, high-performance fiber-reinforced concrete (HPFRC) in coupling beams and walls was evaluated as a means to reduce diagonal and confinement reinforcement. The Specimen $C W-1$ walls were constructed with reinforced concrete $(R C)$ designed to satisfy ACI Building Code (ACI 318-08) seismic provisions. The walls in Specimen $C W-2$ were constructed with HPFRC and reduced shear and confinement reinforcement. Each specimen included one RC and three HPFRC precast coupling beams with span-depth ratios of 1.75 . Both specimens sustained $80 \%$ of the peak lateral strength through loading cycles to at least $2.5 \%$ drift. Inelastic flexural deformations were more concentrated near the foundation in the HPFRC walls than in the RC walls, which led to a higher curvature demand at the base of the HPFRC walls. Although the walls in both specimens exhibited a flexuraldominated behavior, shear distortions in the first story of the walls reached $0.01 \mathrm{rad}$. Detailed data are presented regarding specimen behavior, including wall and coupling beam deformations.

Keywords: confinement; coupled wall; coupling beam; earthquake; fibers; reinforced concrete (RC); shear.

\section{INTRODUCTION}

Reinforced concrete (RC) coupled walls are regularly used as the primary lateral force-resisting system for medium- to high-rise structures. Current building codes require that most coupling beams with span-depth ratios less than 2 be reinforced with heavy confinement reinforcement and diagonal bars designed to resist the entire shear demand. Similarly, walls are designed with dense boundary element confinement reinforcement wherever large inelastic deformations are anticipated. This special beam and wall reinforcement detailing is expected to ensure adequate deformation capacity and delay or prevent non-ductile failures. However, difficulty assembling this reinforcement in a cost-effective manner has motivated numerous studies aimed at finding simpler, more economical alternatives, particularly for coupling beams. Proposed design alternatives have included the use of special reinforcement layouts, such as rhomboid reinforcement layouts, as well as steel and composite concrete-steel coupling beams. ${ }^{1-4}$

The purpose of this study was to investigate whether the use of tensile strain-hardening, high-performance fiberreinforced concrete (HPFRC) allows simplification of reinforcement detailing in coupled walls without compromising deformation capacity. Results from previous reversed cyclic load tests of coupling beams and other structural elements, ${ }^{5-10}$ including isolated walls, have indicated HPFRC can increase shear resistance and confinement in members subjected to high shear and deformation reversals. These effects are attributed to the post-cracking toughness of HPFRC in tension and its response in compression, which resembles that of well-confined concrete. However, there have been no tests of coupled HPFRC structural walls, for which the distribution of base shear stresses and wall deformations differ significantly from those in isolated slender walls.

This paper presents a detailed comparison of the behavior of four-story RC and HPFRC coupled wall specimens, with an emphasis on deformations in the first story of the walls and in the coupling beams.

\section{RESEARCH SIGNIFICANCE}

Data from large-scale tests of coupled walls linked by RC and HPFRC coupling beams are presented. The testing program included the first HPFRC coupled wall test and one of few tests of large-scale T-shaped RC coupled walls. The results presented should be useful to researchers, designers, and code officials interested in the seismic performance and modeling of RC structures constructed with HPFRC.

\section{EXPERIMENTAL PROGRAM}

Two specimens, CW-1 and CW-2, each consisting of two four-story coupled walls, were constructed at approximately one-third-scale and tested under lateral displacement reversals. At this scale, it is expected that test results reasonably represent full-scale structural behavior. A photo of Specimen CW-1, prior to testing, is shown in Fig. 1. Each specimen had four precast coupling beams linking two T-shaped walls oriented with the flanges along the outside edges of the system. An RC coupling beam was used at the second level, whereas HPFRC beams were used at the other three levels. Specimen reinforcement is shown in Fig. 2.

Each specimen was laterally loaded by hydraulic actuators acting through slabs constructed at the second and fourth levels. The slabs were cast beside the precast coupling beams so that the tops of the slab and beam were flush. No reinforcement crossed the joint between the precast beam and slab to simplify construction. Therefore, no interaction between the coupling beams and the adjacent slab was assumed in design. Lateral displacements were applied at the fourth level following the protocol shown in Fig. 3. The lateral force applied to the second level was approximately two-thirds of that at the top. A vertical load of $0.07 A_{g} f_{c}^{\prime}$,

ACI Structural Journal, V. 113, No. 3, May-June 2016.

MS No. S-2012-327.R2, doi: 10.14359/51688822, was received November 26, 2014, and reviewed under Institute publication policies. Copyright (C) 2016, American Concrete Institute. All rights reserved, including the making of copies unless permission is obtained from the copyright proprietors. Pertinent discussion including author's closure, if any, will be published ten months from this journal's date if the discussion is received within four months of the paper's print publication. 


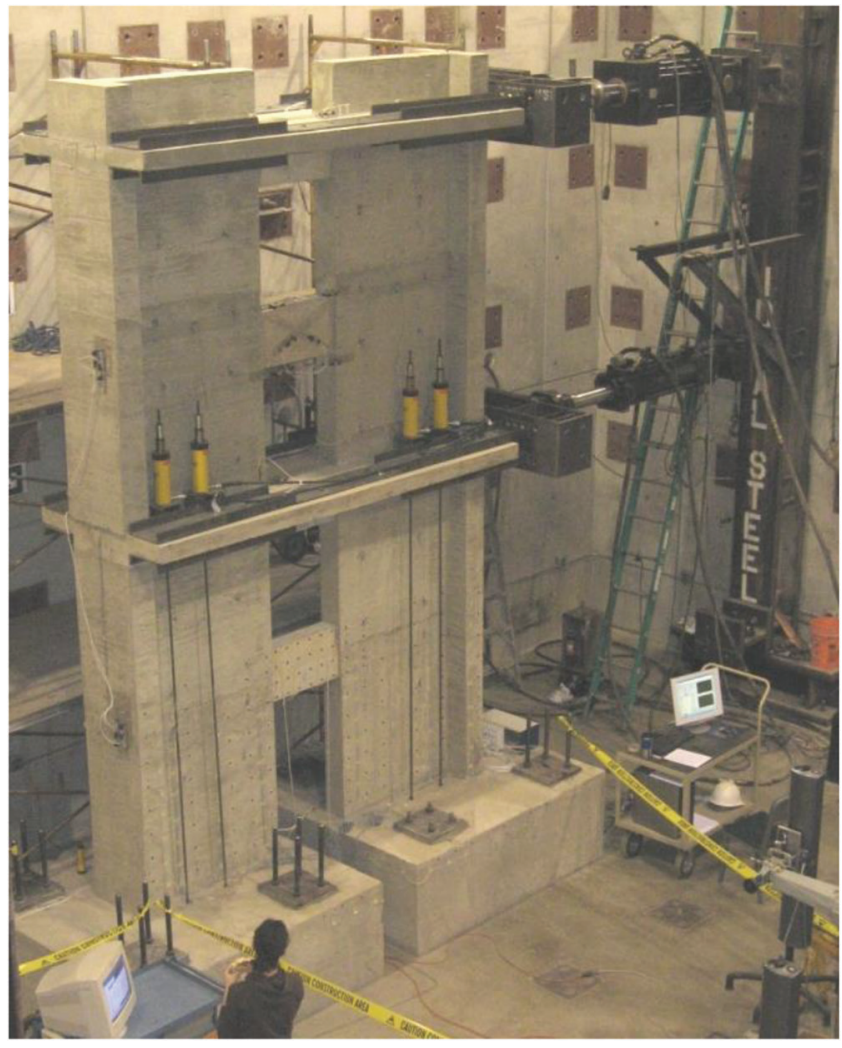

Fig. 1-Coupled wall specimen, before testing.

where $A_{g}$ is the gross cross-sectional wall area and $f_{c}^{\prime}$ is the concrete cylinder strength, was applied at the second level with hydraulic jacks. The vertical load was applied prior to application of lateral displacements and its magnitude checked after each loading cycle. Vertical load could not be applied at the fourth level due to limitations of the test setup. It is believed the location of axial load application did not significantly affect results because the instrumented reinforcement throughout the top two stories of the walls remained elastic.

\section{Specimen CW-1}

The walls of Specimen CW-1 were constructed with regular RC designed to comply with the seismic provisions (Chapter 21) of the 2008 ACI Building Code. ${ }^{11}$ Flexural reinforcement consisted of twelve No. $5(16 \mathrm{~mm})$ flexural bars in the flanges and four No. $6(19 \mathrm{~mm})$ bars in the wall stems. Web reinforcement consisted of two curtains of No. $3(10 \mathrm{~mm})$ bars with vertical and horizontal bars spaced at 7.5 and 7.0 in. (188 and $175 \mathrm{~mm}$ ), respectively (web reinforcement ratios of 0.004 and 0.0045 , respectively). Horizontal reinforcement was selected so the wall shear capacity exceeded the calculated average base shear stress demand of $5.7 \sqrt{ } f_{c}^{\prime}$ psi $\left(0.48 \sqrt{ } f_{c}^{\prime} \mathrm{MPa}\right)$, where $f_{c}^{\prime}$ was taken as $4 \mathrm{ksi}(28$ $\mathrm{MPa})$ and a $\varphi$ value of 1.0 was assumed. The concrete shear stress contribution, $v_{c}$, was assumed to be $2 \sqrt{ } f_{c}^{\prime}$ psi $\left(0.17 \sqrt{ } f_{c}^{\prime}\right.$ $\mathrm{MPa})$. Base shear demand was calculated assuming the coupling beams and wall bases simultaneously reached their moment capacity, taken as the peak moment obtained from a moment-curvature analysis. The constitutive relationships shown in Fig. 4 were used for design.
Boundary element hoops were spaced at $b_{w} / 3$, where $b_{w}$ is the wall thickness of 7 in. $(175 \mathrm{~mm})$. The cross-sectional area of the confinement reinforcement was $130 \%$ and $110 \%$ of that required in ACI- $318^{11}$ for the wall stem and flange, respectively.

To be consistent with ACI-318 ${ }^{11}$ recommendations, all straight coupling beam flexural reinforcement was terminated $3 \mathrm{in} .(75 \mathrm{~mm})$ from the cold joint; a detail that differed from beam specimens tested previously. ${ }^{9}$ The expected peak beam shear stress, assuming the probable moment is reached at both ends, was $5 \sqrt{ } f_{c}^{\prime}$ psi $\left(0.42 \sqrt{ } f_{c}^{\prime} \mathrm{MPa}\right)$. The coupling ratio in Specimen CW-1, neglecting the slabs, was calculated as 0.40 using the following equation

$$
\text { Coupling ratio }=\frac{\left(\sum V_{u, C B}\right) x_{c}}{M_{o}}
$$

where $V_{u, C B}$ is the maximum shear force expected in the coupling beams; $x_{c}$ is the distance between the centroidal axes of the uncracked walls; and $M_{o}$ is the overturning moment capacity of the system.

\section{Specimen CW-2}

Design of Specimen CW-2 was similar to that of Specimen CW-1, with the following changes. Coupling beam reinforcement was extended into the walls of Specimen CW-2, resulting in a predicted maximum coupling beam shear stress of $9 \sqrt{ } f_{c}^{\prime}$ psi $\left(0.75 \sqrt{ } f_{c}^{\prime} \mathrm{MPa}\right)$. The design coupling ratio (neglecting slab coupling) was 0.45 and the predicted average shear stress demand in the walls was $6.4 \sqrt{ } f_{c}^{\prime}$ psi $\left(0.53 \sqrt{ } f_{c}^{\prime} \mathrm{MPa}\right)$, with a specified concrete strength $f_{c}^{\prime}$ of $6 \mathrm{ksi}$ (41 MPa) to be consistent with the expected strength of the HPFRC to be used in the walls.

The first two stories of the walls in Specimen CW-2 were constructed with HPFRC. Due to the tensile strainhardening behavior of HPFRC, $v_{c}$ was assumed to be $4 \sqrt{ } f_{c}^{\prime}$ psi $\left(0.33 \sqrt{ } f_{c}^{\prime} \mathrm{MPa}\right)$ for the HPFRC in the walls, which resulted in the same horizontal transverse reinforcement ratio as in Specimen CW-1 despite the higher base shear stress demand. Two vertical curtains of No. $3(10 \mathrm{~mm})$ bars, spaced at 10.5 in. $(263 \mathrm{~mm})$, were provided (web reinforcement ratio of 0.003$)$, compared to a spacing of $7.5 \mathrm{in} .(188 \mathrm{~mm})$ used in Specimen CW-1. Also, to prevent concentration of inelastic deformations at the cold joint between the walls and the foundation caused by the lack of fibers crossing these joints, three pairs of No. $4(12 \mathrm{~mm})$ dowel bars were placed across the cold joint extending 8 in. $(200 \mathrm{~mm})$ into the wall.

In the east and west wall piers, hoops were spaced at $b_{w} / 2$ and $b_{w}$, respectively (Fig. 2), to evaluate the effectiveness of confinement provided by HPFRC and hoops at different spacings. The confinement reinforcement provided in the east and west wall piers was $90 \%$ and $40 \%$ of that required $^{11}$ for the wall stems and $70 \%$ and $40 \%$ for the flanges, respectively.

\section{Material properties}

Results from flexural tests performed in accordance with ASTM C $1609^{12}$ and compression tests are summarized in Table 1. The conventional concrete used in the walls was 


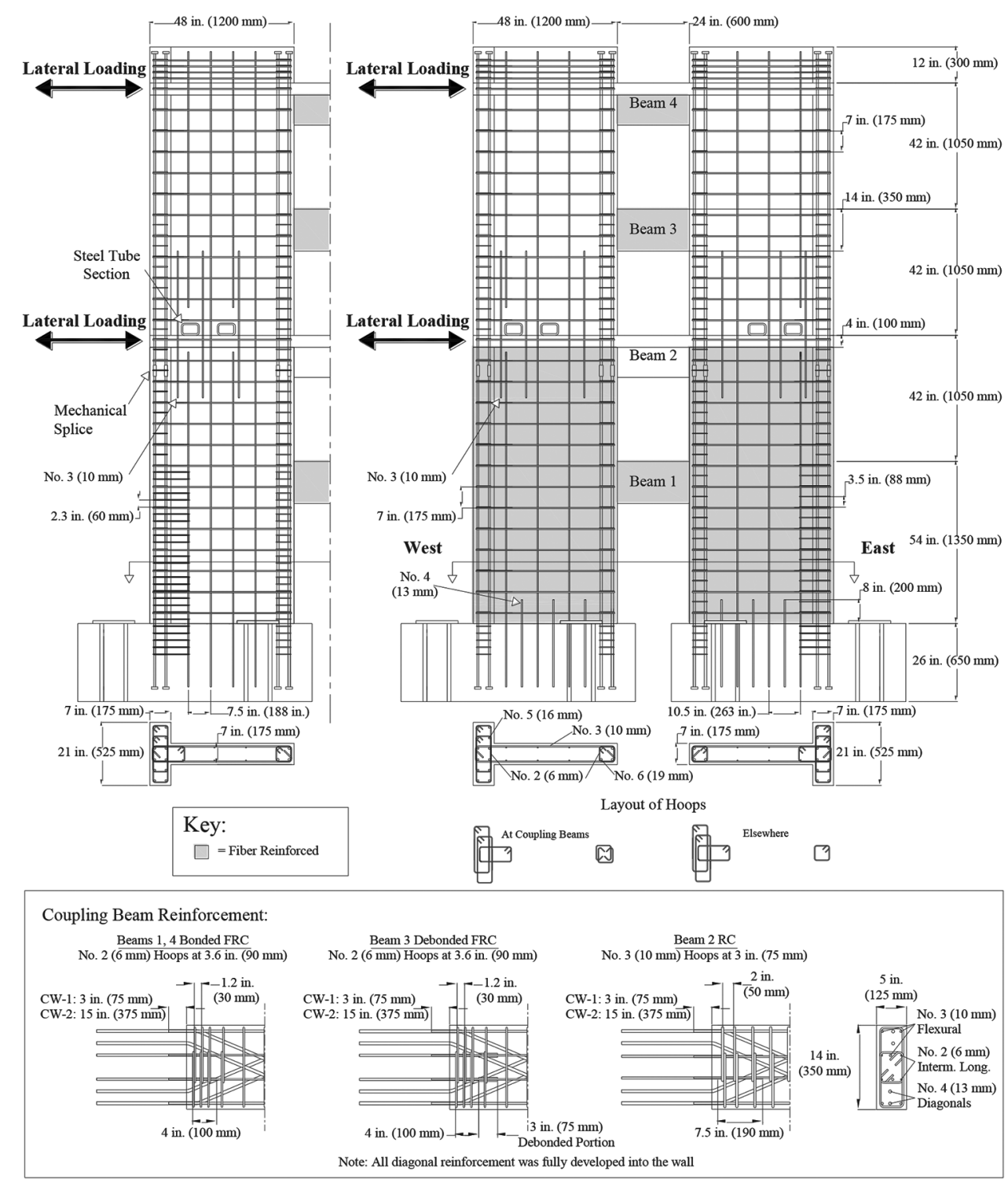

Fig. 2-Specimen reinforcement. Half of Specimen CW-1, which was symmetric, is shown alongside Specimen CW-2.

provided by a local supplier. The HPFRC mixture, developed by Liao et al., ${ }^{13}$ consisted of Type III cement, Type C fly ash, silica sand, crushed limestone aggregate with a maximum nominal diameter of 0.5 in. $(13 \mathrm{~mm})$, water, highrange water-reducing admixture, and viscosity-modifying admixture in proportions of 1:0.875:2.2:1.2:0.8:0.005:0.038 by weight. High-strength hooked steel fibers with a length of 1.2 in. $(30 \mathrm{~mm})$, diameter of 0.015 in. $(0.38 \mathrm{~mm})$, length-to-diameter ratio of 80 , and minimum tensile strength of $330 \mathrm{ksi}(2300 \mathrm{MPa})$ were added at a volume fraction, $V_{f}$, of $1.5 \%$. This mixture was shown ${ }^{13}$ to exhibit strain-hardening behavior under direct tension, as well as adequate workability.

The base of the walls in Specimen CW-2 (approximately the lower 48 in. [1200 mm]) were cast using concrete from a local ready mix concrete supplier with fibers added to the truck at the laboratory. Due to poor workability of the ready mix concrete, water was added on-site. An error caused excessive water to be added, however, resulting in a compressive strength of $2.7 \mathrm{ksi}(19 \mathrm{MPa})$ at 28 days. HPFRC

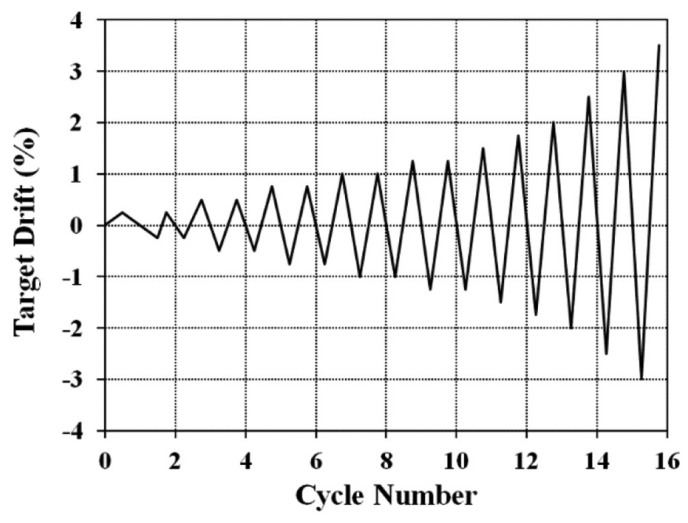

Fig. 3-Coupled wall diplacement protocol.

batched at the laboratory was thus used to construct the rest of the fiber-reinforced concrete walls. A design $f_{c}^{\prime}$ of $6 \mathrm{ksi}$ (41 MPa) is used herein for calculations of normalized shear stress in the base of Specimen CW-2. Compressive cylinder strength results are used for other calculations. Further details are available in Lequesne. ${ }^{14}$ 

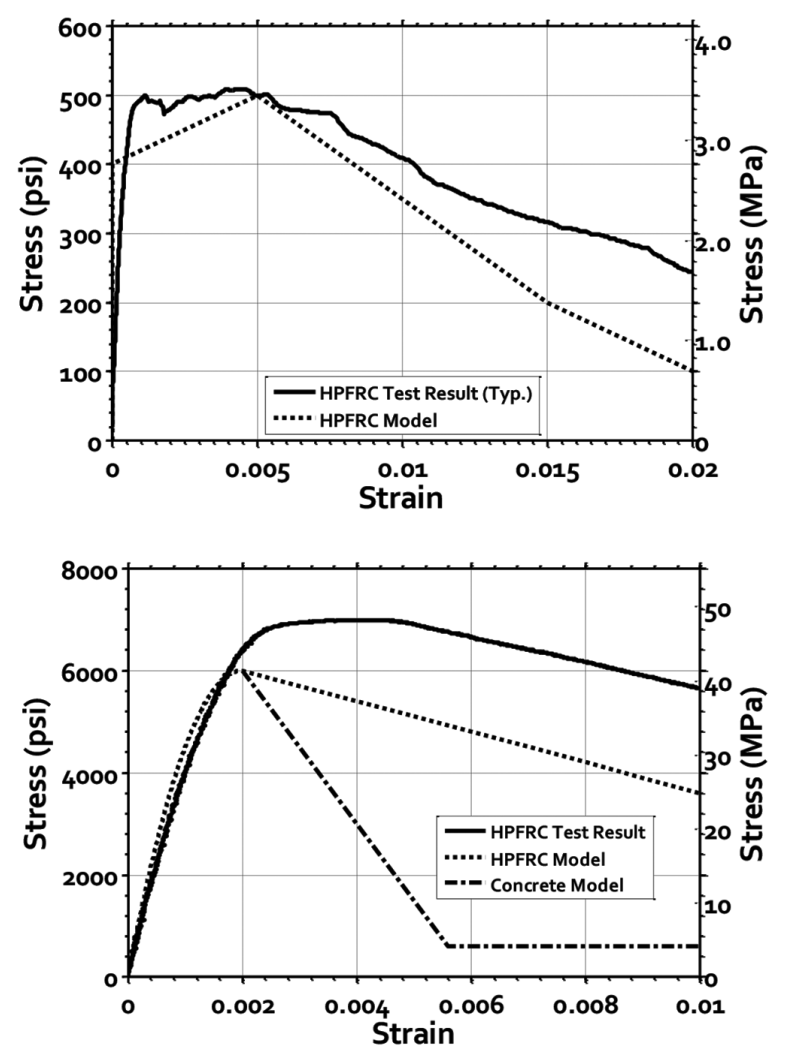

Fig. 4-Constitutive relationship of concrete in tension (top) and compression (bottom). Tension behavior of plain concrete was neglected.

Mild deformed steel reinforcement with minimum yield and ultimate strengths of 60 and $90 \mathrm{ksi}(415$ and $620 \mathrm{MPa})$, respectively, was used for the No. $3(10 \mathrm{~mm})$ bars and larger. The No. $2(6 \mathrm{~mm})$ reinforcement used to confine the wall boundary elements was smooth steel wire with a yield strength, determined by the $0.2 \%$ offset method, and ultimate strength of 64 and $73 \mathrm{ksi}$ (440 and $500 \mathrm{MPa}$ ), respectively.

\section{RESULTS OF COUPLED WALL TESTS}

Test results are summarized in Table 2. Both specimens performed in a stable and ductile manner, retaining $80 \%$ of peak lateral strength to a drift of at least $2.5 \%$ in both loading directions (Fig. 5), while sustaining average base shear stresses up to 5.6 and $7.4 \sqrt{ } f_{c}^{\prime}$ psi $\left(0.46\right.$ and $\left.0.61 \sqrt{ } f_{c}^{\prime} \mathrm{MPa}\right)$ in Specimens CW-1 and CW-2, respectively. System drift was calculated as the average lateral wall displacement at the fourth-level slab divided by the height of the slab above the foundation. Calculated drift was corrected for foundation movement, including sliding (less than 0.5 in. [13 mm]) and uplift. Additional results are available elsewhere. ${ }^{9,14}$

\section{Progression of damage}

Wall damage - In drift cycles up to $0.75 \%$, predominantly diagonal cracking was observed in the coupling beams and first two wall stories. Diagonal cracks were spaced at approximately 5 and 2 in. (125 and $50 \mathrm{~mm}$ ) in the RC and HPFRC walls, respectively (Fig. 6). Flexural cracking was noted in the base of the tension wall and in the ends of the coupling beams. Strains exceeding the yield strain determined through coupon tests were measured in the wall flexural reinforcement and the longitudinal and diagonal coupling beam reinforcement (except for the cutoff longitudinal bars in Specimen CW-1).

At drifts between 0.75 and $1 \%$, flexural cracking became more pronounced in the ends of the coupling beams and wall bases up to a height equal to the wall length. Strains exceeding yield were measured in some of the cutoff longitudinal reinforcement near the end of the coupling beams in Specimen CW-1.

Drifts larger than $1 \%$ caused little new cracking or opening of diagonal cracks, as deformations appeared to concentrate in widening flexural cracks.

When Specimen CW-2 was pushed to $2.5 \%$ drift, a shear-compression failure occurred in the HPFRC wall with confinement reinforcement spaced at $b_{w}$ (west wall). This failure appeared to start in the web near the first story coupling beam, where crushing of the weak concrete (refer to the "Material properties" section) was observed. This was followed by yielding of transverse wall reinforcement (as indicated by strain gauges) and then failure of the compression zone. This was the only yielding recorded in any transverse wall reinforcement.

Beam damage-Figure 7 shows photos of select coupling beams after termination of the tests. Damage in the coupling beams in Specimen CW-1 concentrated near the beam-towall interface where longitudinal reinforcement was cut off (Fig. 7(a)). Although coupling beam shear forces could not be measured, the chord rotation at which connection damage caused a loss of beam strength can be inferred from the data. Strain gauges located on midspan hoops in the coupling beams at the second and third levels of Specimen CW-1 recorded maximum strains on the order of 0.001 during loading cycles, causing peak chord rotations of approximately $3.75 \%$ and $5 \%$, respectively. At chord rotations of approximately $4 \%$ and $7 \%$, the same gauges indicated reduced strains in the RC and HPFRC coupling beams, respectively. This is consistent with reduced shear force demands.

The Specimen CW-2 coupling beams, with fully developed longitudinal reinforcement, exhibited flexural and shear cracking throughout their spans. Hoop strain measurements in the second-, third-, and fourth-level coupling beams exceeded the yield strain at chord rotations of $3 \%, 7 \%$, and $3 \%$, respectively (midspan hoop strains were not measured at the first story), and increased in the HPFRC beams until termination of the test. Hoop strains in the RC beam diminished at chord rotations exceeding $4 \%$, to approximately 0.001 at the end of the test. The RC coupling beam exhibited significantly more damage than the three HPFRC coupling beams throughout the test (Fig. 7(b)).

Slab damage-Flexural cracks were observed on the top and bottom surfaces of the slabs that extended, perpendicular to the direction of loading, from the beam-to-wall interface to the slab edge. The elevation of the top surfaces of the coupling beams and slabs, which were cast flush, did not differ by more than 0.1 in. $(2.5 \mathrm{~mm})$ throughout either test. There was no visible damage associated with the lack of reinforcement between the slab and beam. 
Table 1-Concrete compressive and flexural strengths 28 days after casting, and on day of specimen testing, ksi (MPa)

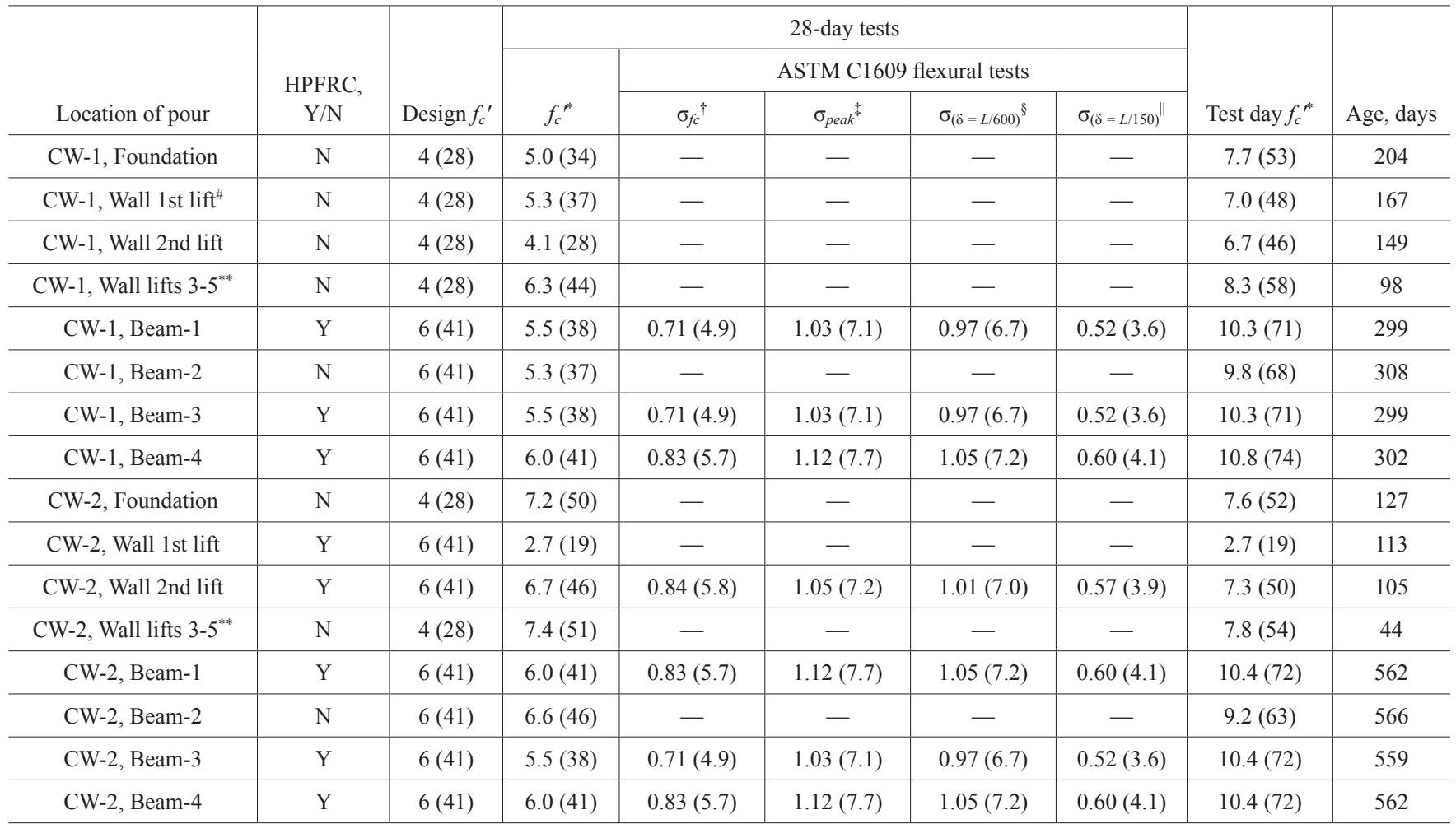

${ }^{*}$ Cylinders with diameter and height of 4 and 8 in. (100 and $\left.200 \mathrm{~mm}\right)$, respectively.

${ }^{\dagger} \sigma_{f c}$ is first cracking strength.

${ }^{*} \sigma_{\text {peak }}$ is peak equivalent flexural stress per ASTM C1609.

${ }^{\S} \sigma_{(\delta=L / 600)}$ is equivalent flexural stress at midspan deflection of $L / 600 ; L$ is span length $=18$ in. $(450 \mathrm{~mm})$.

${ } \sigma_{(\delta=L / 150)}$ is equivalent flexural stress at midspan deflection of $L / 150$.

${ }^{\#} 1$ lift $=1$ story, except Lift 5 , which was portion of wall above fourth-floor slab.

** Values are averaged for three lifts, except for "Age, days," which reports age of Lift 5 at testing.

Table 2-Summary of coupled wall test results

\begin{tabular}{c|c|c}
\hline Specimen & CW-1 & CW-2 \\
\hline $\begin{array}{c}\text { Measured } V_{\text {max }} * \\
\text { kip }(\mathrm{kN})\end{array}$ & $317(1410) /-309(-1370)$ & $358(1590) /-384(-1710)$ \\
\hline $\begin{array}{c}V_{\max } /\left(2 b_{w} l_{w} \vee f_{c}\right)^{\dagger}, \\
\mathrm{psi}(\mathrm{MPa})\end{array}$ & $5.6(0.46) /-5.5(-0.45)$ & $6.9(0.57)^{\ddagger} /-7.4(-0.61)^{\ddagger}$ \\
\hline$\delta^{\S}$ at $V_{\max }, \%$ & $1.25 /-1.42$ & $1.31 /-1.37$ \\
\hline$\delta_{\max }, \%$ & $2.6 /-2.8$ & $2.5 /-3.5$ \\
\hline
\end{tabular}

${ }^{*} V_{\max }$ is peak shear force.

$\dagger_{w}$ is horizontal base length of each wall segment.

${ }_{c}{ }^{\prime}=6 \mathrm{ksi}(41 \mathrm{MPa})$ was used for this calculation, not strength at test day.

$\S_{\delta}$ is drift.

${ }^{\|} \delta_{\max }$ is largest applied drift with $\geq 80 \%$ strength retention.

\section{Wall deformations}

Discussion of wall deformations will focus on the first story of the system because strain gauge data showed that deformations in the three upper stories of the walls remained within the cracked-elastic range throughout the tests. In the first story, deformation data were collected using an array of optical markers placed on an approximately 6 in. $(150 \mathrm{~mm})$ grid (Fig. 8). For analysis, the optical markers were grouped into horizontal rows, or "strips." The terms "compression wall" and "tension wall" are used to refer to the wall pier subjected, at a point in the loading sequence, to either increased compression or tension due to coupling.

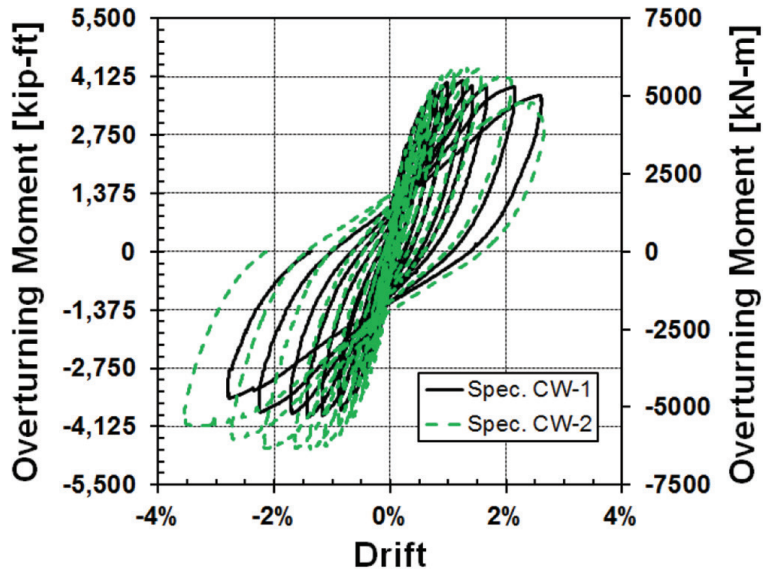

Fig. 5-Overturning moment versus lateral drift response of coupled wall specimens. ${ }^{9}$

Principal strains-Based on measured optical marker displacements, the average state of strain was calculated for each rectangle in the grid on the wall stem. Principal strains calculated for Strips 2 through 7 are plotted in Fig. 9 for Specimen CW-2 at $-0.9 \%$ and $-2.2 \%$ drift (negative drift is toward the east, or right side of the figure). Strips 1,8 , and 9 are not included because the foundation cold joint and the irregular instrumentation grid skewed results. Principal strains are plotted as arrows oriented parallel to the principal axes and proportional in length to the magnitude of strain. 


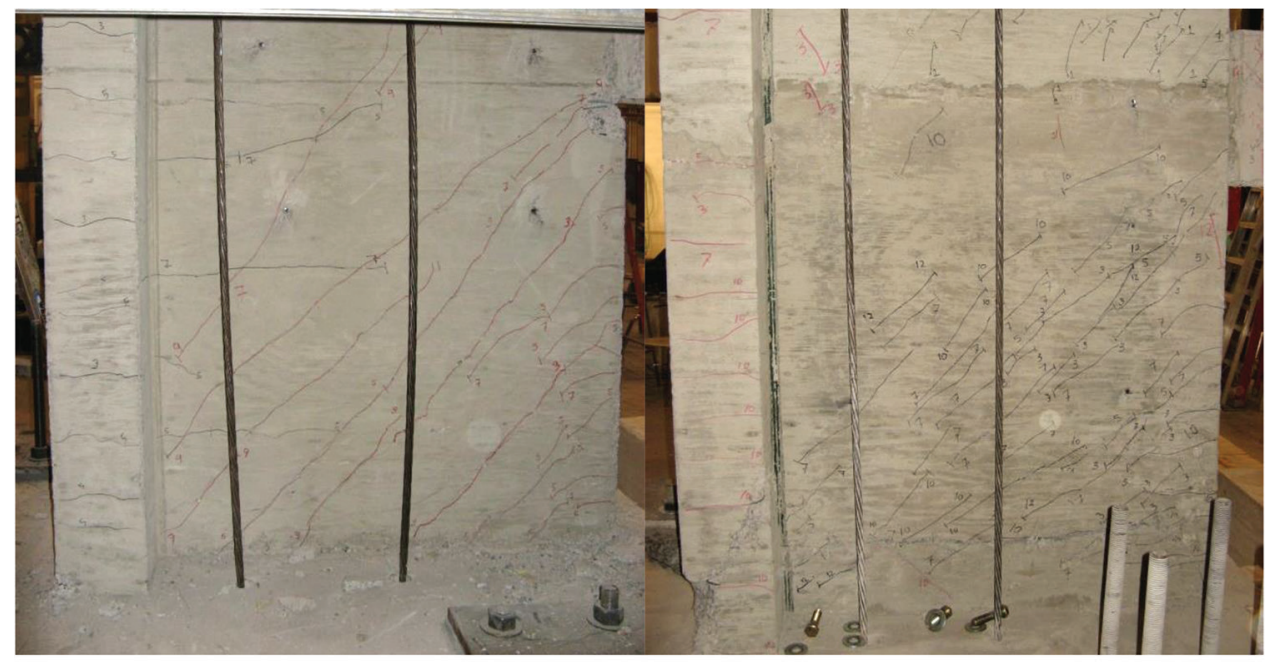

(a) Specimen CW-1 (reinforced concrete)

(b) Specimen CW-2 (HPFRC)

Fig. 6-Damage to walls after test.

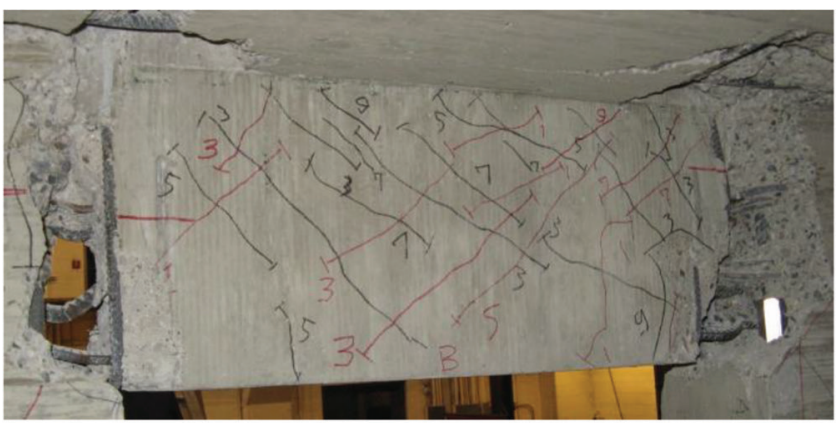

(a) Specimen CW-1: Typical beam damage ( $2^{\text {nd }}$ floor beam pictured)
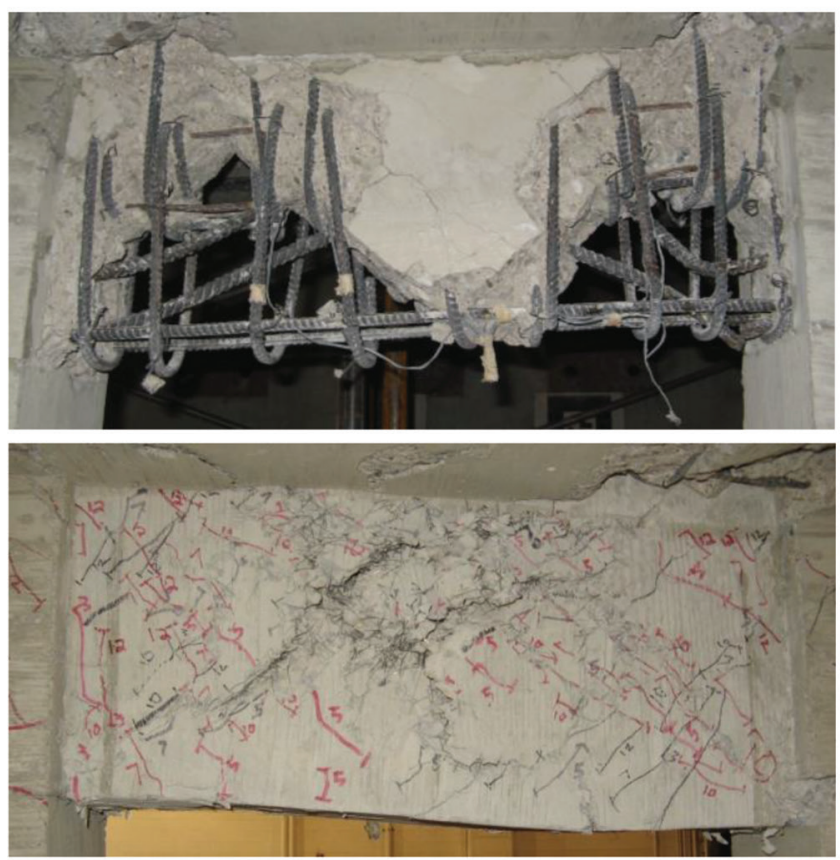

(b) Specimen CW-2: Reinforced Concrete

( $2^{\text {nd }}$ floor) beam, top, and HPFRC ( $4^{\text {th }}$ floor $)$ beam, bottom

Fig. 7-Damage to coupling beams after termination of tests.

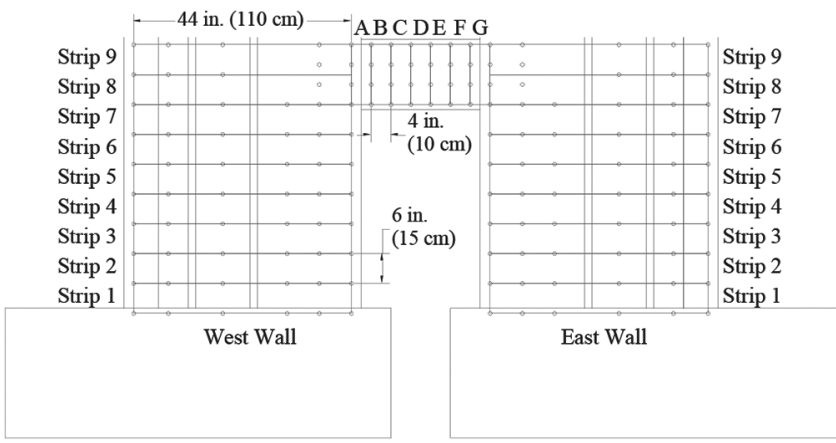

Fig. 8-Schematic of optical marker grid fixed to surface of first story of each specimen.

Outward and inward pointing arrows indicate tensile and compressive strains, respectively.

The principal strain distributions at $-0.9 \%$ and $-2.2 \%$ drift, shown in Fig. 9, were similar despite substantially larger magnitudes at $-2.2 \%$ drift. In both walls, the distributions were generally consistent with deformations expected under combined flexure and shear. In the tension wall (west wall; left side of Fig. 9), the calculated principal strains at $-0.9 \%$ drift were small, with a maximum major principal strain of 0.0029 (tension is positive) calculated in the stem next to the flange in Strip 3. At $-2.2 \%$ drift, calculated principal strains were much larger throughout; particularly in the flange and near the wall base, where major principal strains as large as 0.021 were calculated in the tension wall.

In the compression wall (east wall; right side of Fig. 9), calculated principal strains were larger. At $-0.9 \%$ drift, the maximum major principal strain calculated in the compression wall was 0.0099, occurring in Strip 2 in the stem. The largest calculated major principal strain at $-2.2 \%$ drift, 0.035 , again occurred in Strip 2 in the stem. At both $-0.9 \%$ and $-2.2 \%$ drift, the largest minor principal strains, -0.0033 and -0.0070 , respectively, occurred in the stem of the compression wall near the coupling beam joint (Strip 7). These were larger than in Specimen CW-1, which exhibited a peak minor principal strain at the coupling beam joint of -0.0012 at a drift 


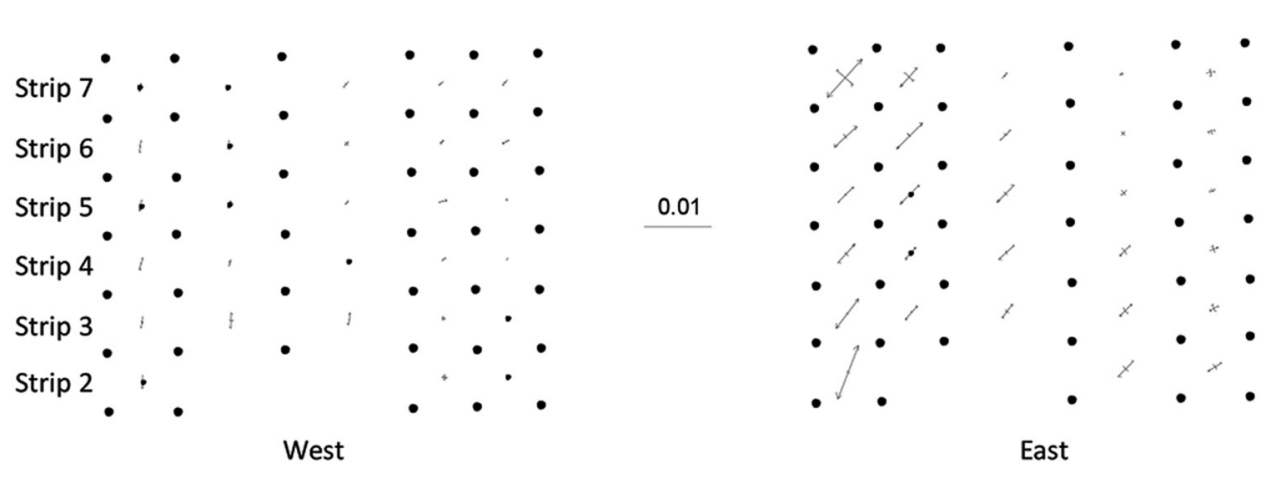

(a) Specimen CW-2, $-0.9 \%$ drift

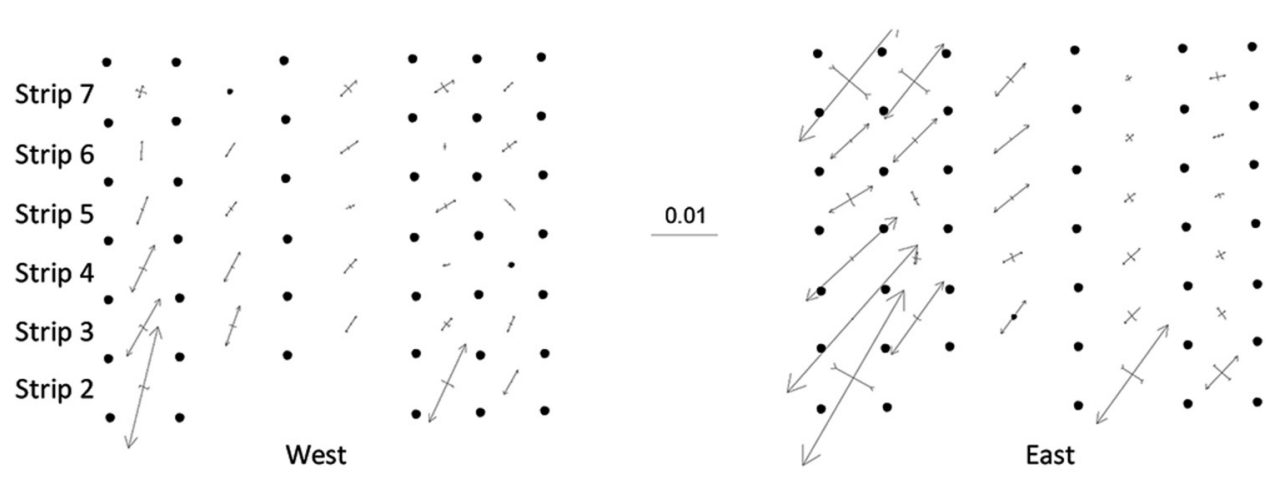

(b) Specimen CW-2, $-2.2 \%$ drift

Fig. 9-Principal strains calculated in first story of Specimen CW-2 at selected drifts. Arrows are drawn parallel and proportional to calculated principal strains. Outward pointing arrows indicate tension.

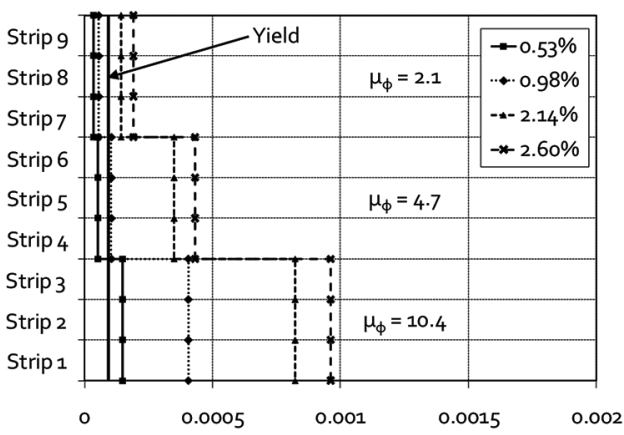

(a) Specimen CW-1

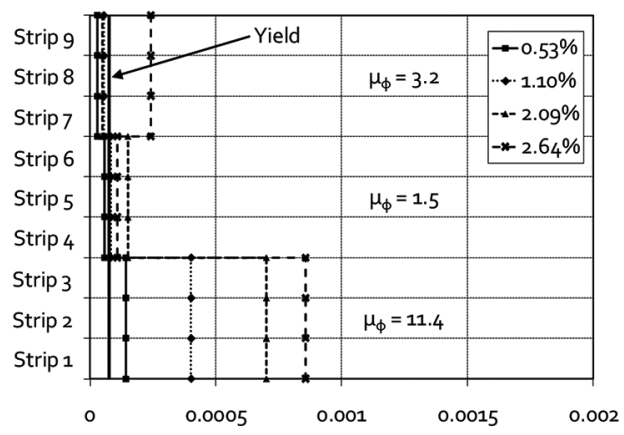

(b) Specimen CW-2

Fig. 10-Wall curvature (rad/in.) calculated for first story of west wall piers at selected drifts causing wall pier compression.

of $-0.9 \%$. In Specimen CW-1, a peak minor principal strain of -0.0026 was calculated at $-2.2 \%$ drift in Strip 2 , in the stem of the compression wall. As expected, major (tension) strains were significantly greater than minor (compression) strains throughout the tests due to cracking and permanent tensile deformations due to reinforcement yielding.

Curvatures - Curvatures were calculated for each strip by dividing the change in rotation calculated between rows of markers by the initial distance between the considered rows. These curvatures were then averaged across groups of three strips (1 through 3, 4 through 6, 7 through 9) to reduce scatter caused by cracking. Figure 10 shows the curvatures calculated for the west wall pier at selected drifts. Only data from cycles causing wall pier compression are shown. Similar trends were observed in the tension walls, although curvatures were greater in the compression wall. This is believed to be the result of small displacements of the tension-side foundation that reduced the tension-side wall deformation demands.

A trend of larger curvatures near to the foundation is clear. Maximum curvature ductility $\mu_{\varphi}$ between 1 and 3 (occurring in the last loading cycle for each wall pier) was calculated at the level of the first story coupling beam, whereas $\mu_{\varphi}$ values as high as 11 were calculated within $17 \mathrm{in}$. $(425 \mathrm{~mm})$, or $3 l_{w} / 8$, of the foundation in the west wall piers (Fig. 10). Curvature ductility $\mu_{\varphi}$ was calculated by dividing the maximum curvature calculated from marker displacement measurements by the theoretical yield curvature $\varphi_{y}$. The theoretical yield curvature was calculated using the constitutive relationships shown in Fig. 4. 
The average curvature ductility calculated in the lower 17 in. $(425 \mathrm{~mm})$ of each wall pier for every drift half-cycle in which coupling caused increased compression is shown in Fig. 11. Curvature ductilities were similar throughout the tests of the RC and HPFRC walls, with slightly higher ductility demand in the base of the HPFRC walls. The higher curvature ductility calculated at the base of the HPFRC walls coincided with lower curvature demands further from the foundation - evidence of more concentrated rotations (this trend is more pronounced if strips are considered individually rather than in groups of three). The maximum calculated curvature ductilities, exceeding 10 in most cases and 20 in the case of the east wall pier in the HPFRC system

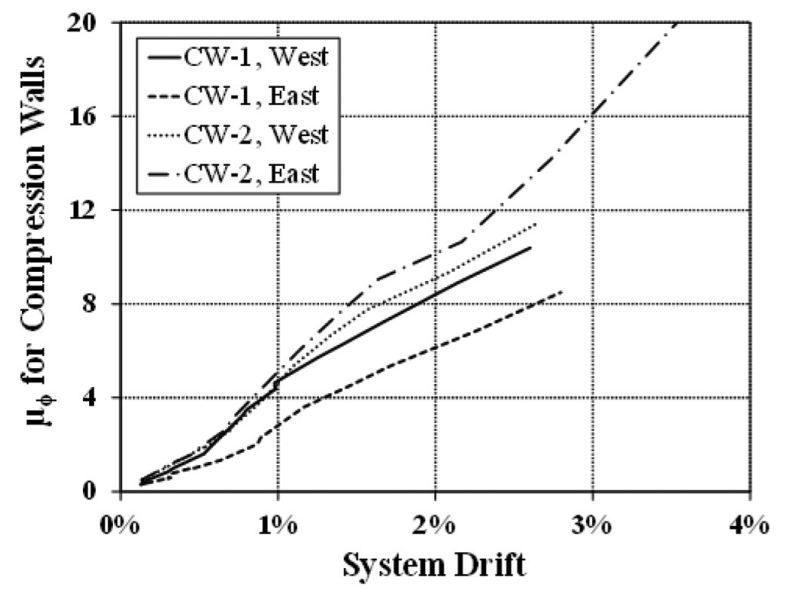

Fig. 11-Curvature ductility in base of compression wall piers. (with confinement spacing at $b_{w} / 2$ ), can be considered large curvature demands for walls subjected to compression. That no buckling or compression failures were observed is evidence of the adequacy of both the special boundary element confinement used in the RC walls and the wider confinement reinforcement spacing provided in the HPFRC wall specimens.

Boundary element longitudinal strains - Average boundary element axial strains were calculated using displacements of optical markers mounted 1.5 in. $(38 \mathrm{~mm})$ from the outside edges of the walls. Within the first three strips (a height of 17 in. [425 mm], or $3 l_{w} / 8$, that included the interface with the foundation), maximum average tensile strains of 0.040 and 0.056 were calculated in the stems of the concrete and HPFRC walls, respectively. Under compression, maximum average strains in the stems of the walls were between -0.0017 and 0.0024 for the $\mathrm{RC}$ walls and between -0.0060 and 0.0044 for the HPFRC walls (compressive strains are negative). The positive strains calculated in the stem under compression are due to residual deformations from cracking and reinforcement yielding in previous loading cycles.

In the flanges of the walls, calculated maximum tensile strains were approximately 0.025 in the RC walls and 0.040 in the HPFRC walls. The larger average tensile strains calculated in the HPFRC walls are consistent with greater concentration of flexural rotations near the base. In both specimens, larger tensile strains were calculated in the wall stem than in the flanges. Flanges under compression exhibited a peak compressive strain of -0.0033 and -0.012 in the RC and HPFRC walls, respectively - much larger than in the wall stems.

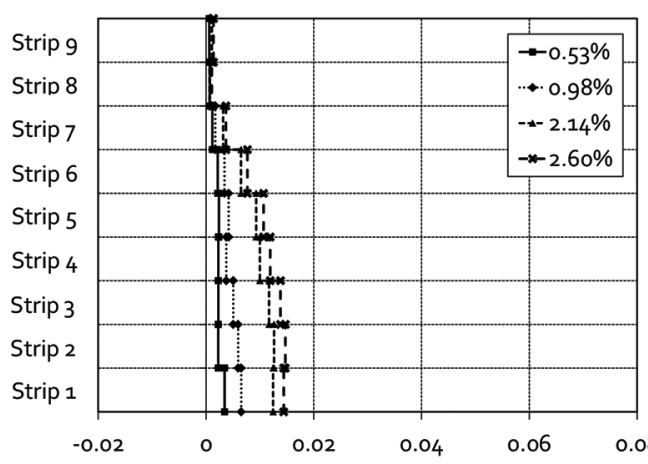

(a) Specimen CW-1, West Wall

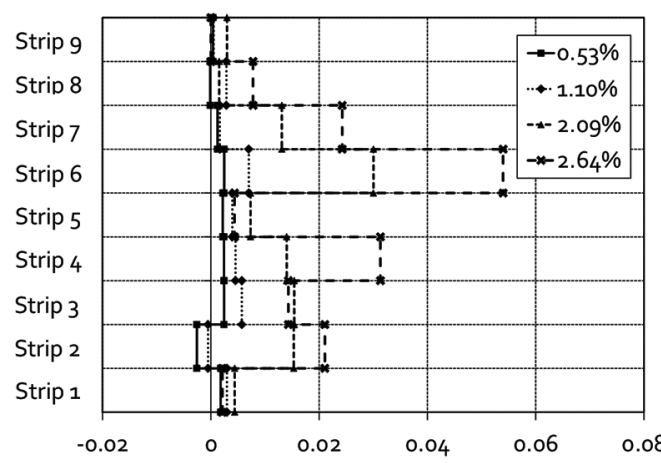

(c) Specimen CW-2, West Wall

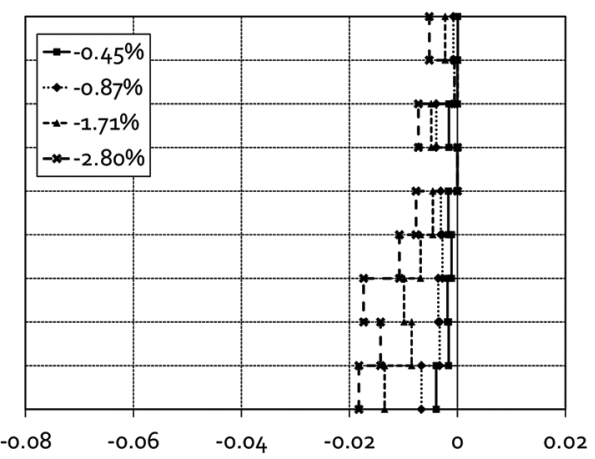

(b) Specimen CW-1, East Wall

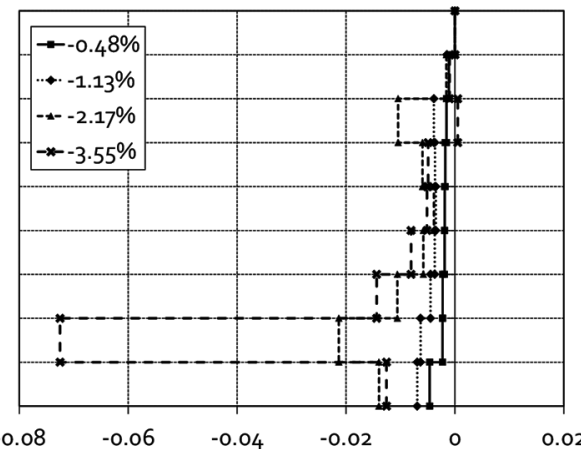

(d) Specimen CW-2, East Wall

Fig. 12-Wall shear distortion (rad) calculated for first story of walls at selected drifts causing wall pier compression. 


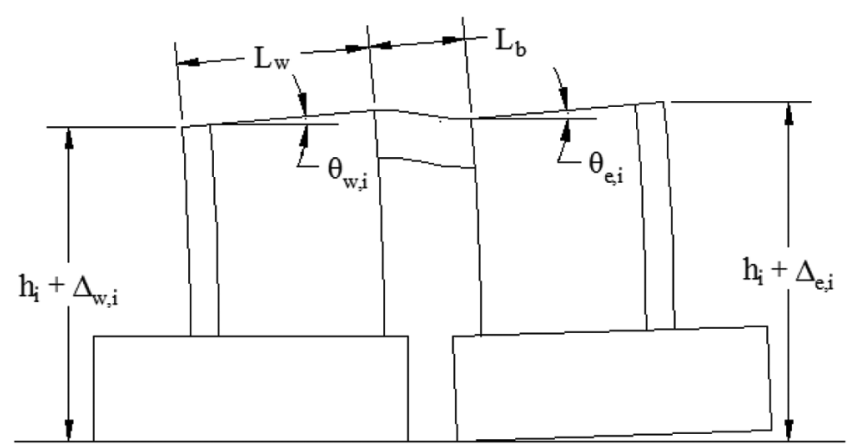

Fig. 13-Parameters for calculating beam chord rotation at level $\mathrm{i}$.

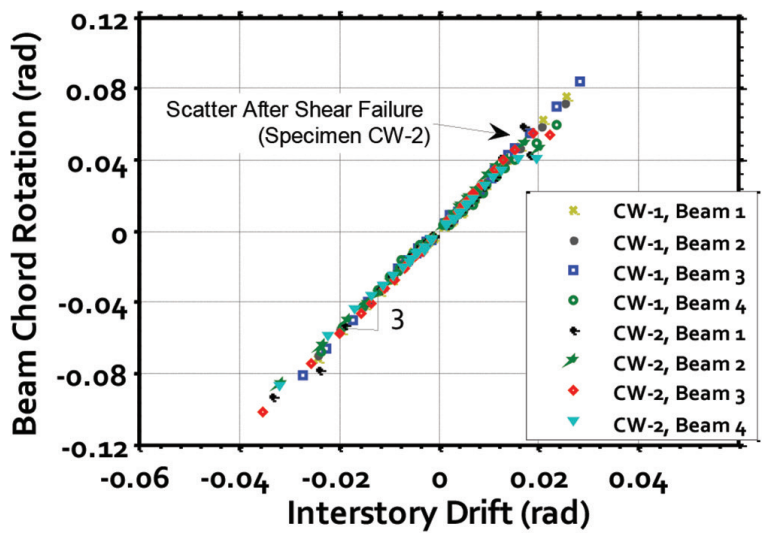

Fig. 14-Beam chord rotation versus interstory wall drift.

Shear distortions-Shear distortions were calculated for each rectangle of the grid shown in Fig. 8 and averaged to calculate the average shear distortion per strip. These are plotted in Fig. 12 for selected drift cycles that caused wall pier compression. At approximately $0.5 \%$ drift, one strip near the base of each wall exhibited a shear distortion approaching $0.005 \mathrm{rad}$. Strips 1 through 3 in both specimens exhibited an average distortion of $0.005 \mathrm{rad}$ at approximately $1 \%$ drift. Average shear distortions exceeded $0.01 \mathrm{rad}$ in both specimens at a drift of $2 \%$, indicating that shear deformations were important despite the dominant flexural mechanism. It was observed that average shear distortions increased near the foundation where flexural rotations were large. This was attributed to reduced shear stiffness caused by flexural rotations. The largest shear distortions, in Strips 6 and 2 of the west and east walls of Specimen CW-2, respectively, resulted from sliding along cracks in later drift cycles. Distortions in Strip 6 of the west wall of Specimen CW-2 coincided with a web shear-compression failure that initiated in this strip. Distortions in Strip 2 of the east wall coincided with a concentration of plastic rotations at the location of dowel bar reinforcement termination.

In general, the same trends were observed in the tension walls, except that shear distortions were approximately half as large. Although higher shear stiffness would be expected on the compression side, the combination of base shear forces shifting to the compression wall and smaller deformation demands in the tension wall due to small foundation movement are believed to explain these smaller shear distortions. The shift of base shear force was not measured.

\section{Coupling beam deformations}

The first-story coupling beam was instrumented with a grid of markers spaced at 4 in. $(100 \mathrm{~mm})$, shown in Fig. 8. Flexural and shear deformations in the beam were calculated using measurements from this instrumentation. Calculation of coupling beam deformations at other levels was more limited due to slab obstructions and limitations of the instrumentation systems.

Chord rotations - Coupling beam chord rotation at level $i$ was calculated using the following equation

$$
\theta_{\text {chord }, i}=\frac{\left(\Delta_{w, i}+\theta_{w, i} L_{w}\right)-\left(\Delta_{e, i}-\theta_{e, i} L_{w}\right)}{L_{b}}+\frac{\left(\theta_{w, i}+\theta_{e, i}\right)}{2}
$$

where $\Delta_{e, i}$ and $\Delta_{w, i}$ are the change in elevation of the outside edges, relative to the laboratory floor, of the east and west walls at coupling beam level $i ; \theta_{e, i}$ and $\theta_{w, i}$ are the east and west wall rotations at coupling beam level $i$; and $L_{w}$ and $L_{b}$ are the horizontal length of the wall piers and coupling beams, respectively. These parameters are illustrated in Fig. 13.

Coupling beam chord rotations were approximately three times greater than the interstory drift, calculated as $\left(\theta_{e, i}+\theta_{w, i}\right) / 2$ (Fig. 14). This amplification of beam chord rotation was approximately equal to the ratio of the distance between wall neutral axes and beam length. This ratio was calculated to be 2.9 using the theoretical distance between wall neutral axes at nominal wall capacity as the numerator and 3.4 using the distance between uncracked wall centroids. For the specimens tested, coupling beam chord rotations were between approximately 3 and $4.5 \%$ at system drifts of 1 to $1.5 \%$. At system drifts of $2.8 \%$ in Specimen CW- 1 and $3.5 \%$ in Specimen CW-2, coupling beams exhibited chord rotations of $8 \%$ and $10 \%$, respectively.

Flexural rotations-Flexural rotations were calculated for seven strips along the length of the first story coupling beam (Fig. 15). Strips A and G encompassed the beam-towall interface. Flexural rotations were generally near zero at midspan and increased closer to the wall interface, with large flexural rotations (due to reinforcement strain penetration) occurring at the beam-to-wall connection in both specimens. Rotations concentrated at a weak plane that developed in the connections in Specimen CW-1, near the end of the precast section, where longitudinal reinforcement was cut off. Development of the flexural reinforcement in Specimen $\mathrm{CW}-2$, on the other hand, forced more deformations away from the connection and into the beam span.

Shear distortions - Calculated coupling beam shear distortions are shown in Fig. 16. Average shear distortions were large, exceeding $0.01 \mathrm{rad}$ in almost all cases when coupling beam chord rotation exceeded $4 \%$ and $0.02 \mathrm{rad}$ in many cases prior to termination of the tests. Because sliding shear displacements could not be differentiated from "true" shear distortion, the shear distortions plotted for Strips A and G may include sliding displacements occurring at either the precast beam-to-wall interface or along wide flexural cracks near the connection. At coupling beam chord rotations of approximately $7 \%$, shear distortions (predominantly sliding) at the beam ends accounted for approximately $0.25 \mathrm{in}$. $(6 \mathrm{~mm})$ of beam displacement, $15 \%$ of total deformations. 


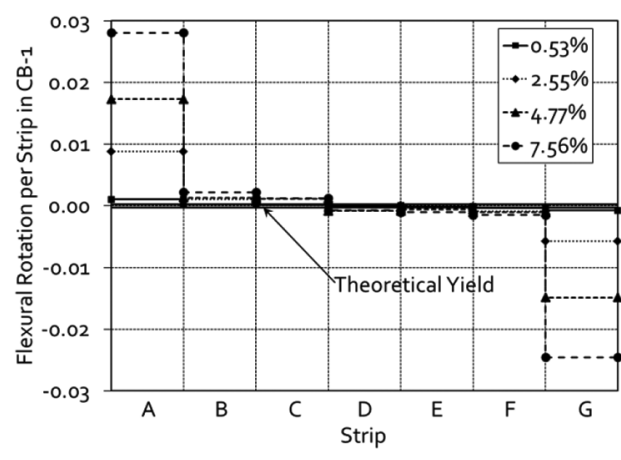

(a) Specimen CW-1

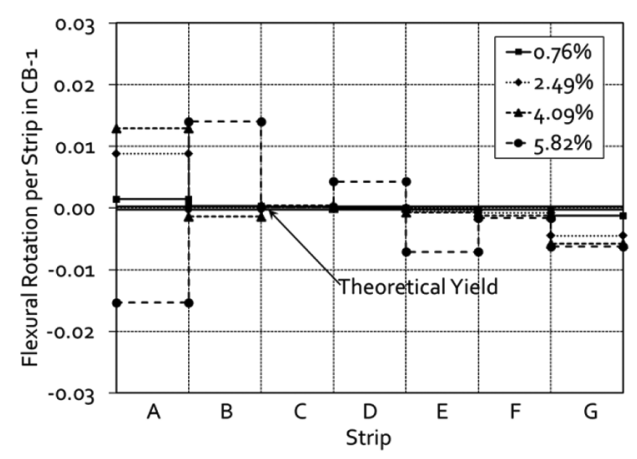

(b) Specimen CW-2

Fig. 15-Average flexural rotation (rad), per strip, in first-story (HPFRC) coupling beams at selected beam chord rotations.

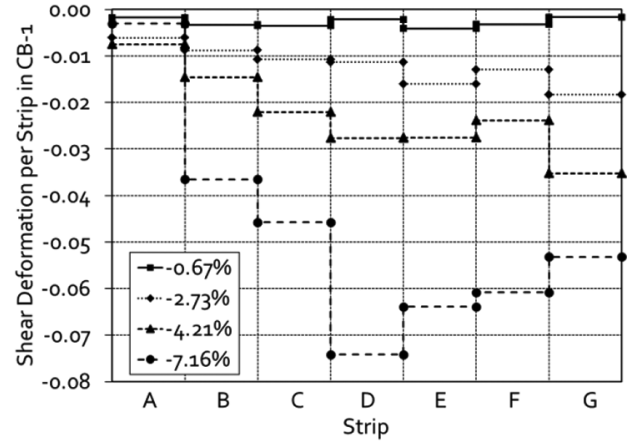

(a) Specimen CW-1

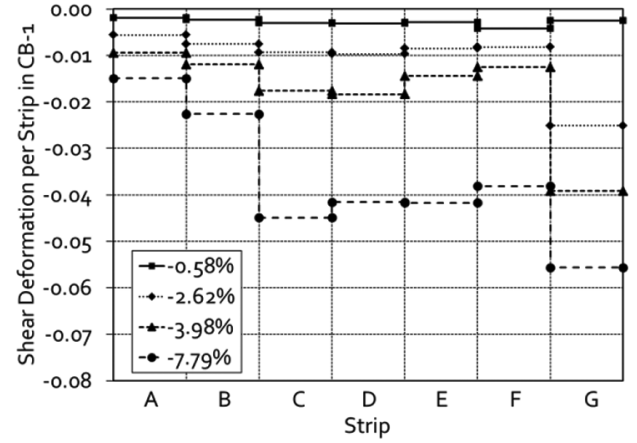

(b) Specimen CW-2

Fig. 16-Average shear distortion (rad), per strip, in first-story (HPFRC) coupling beams at selected beam chord rotations.

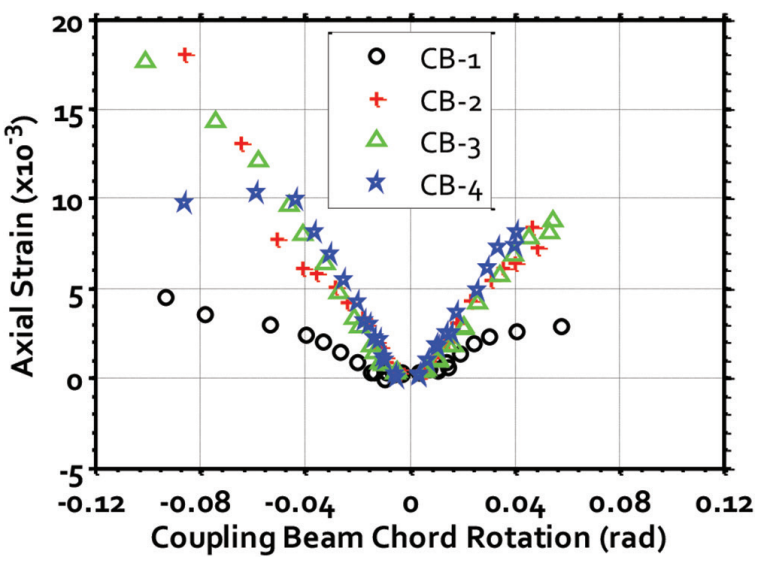

Fig. 17-Axial strain versus chord rotation of Specimen $C W-2$ coupling beams.

It was estimated that sliding and "true" shear distortion contributed between 20 and $70 \%$ of total deformation in Specimen CW-1, depending on loading history, and approximately $50 \%$ of total beam deformations in Specimen CW-2.

Axial strain-Average axial strain was calculated in each coupling beam throughout the tests. Axial strains in the coupling beams of Specimen CW-2 are plotted against coupling beam chord rotation in Fig. 17. With the exception of the first-story coupling beam (CB-1), which exhibited maximum strains of 0.005 , average axial strains between 0.005 and 0.015 were calculated at chord rotations between 2 and $8 \%$ in the negative loading direction. The lower peak drift applied in the positive loading direction, due to the shear failure in the west wall pier late in the test, resulted in peak coupling beam chord rotations and axial strains of approximately 0.06 and 0.01 , respectively. Similar trends were observed in Specimen CW-1, except that the first story beam exhibited negative strains (shortening) at chord rotations exceeding $3 \%$ because of a direct strut that developed between the second level loading point and the compression wall foundation.

\section{SUMMARY AND CONCLUSIONS}

Detailed results are presented from tests of two coupledwall specimens consisting of precast $\mathrm{RC}$ and HPFRC coupling beams joining walls constructed with either RC or HPFRC. Specimen CW-1, with RC walls complying with ACI Building Code ${ }^{11}$ seismic provisions, retained $80 \%$ of its capacity to $2.6 \%$ drift while sustaining average base shear stress demands up to $5.6 \sqrt{ } f_{c}^{\prime}$ psi $\left(0.46 \sqrt{ } f_{c}^{\prime} \mathrm{MPa}\right)$. Specimen CW-2, with HPFRC walls, confinement reinforcement spaced at $b_{w} / 2$ and $b_{w}$, and a design concrete shear stress of $4 \sqrt{ } f_{c}^{\prime}$ psi $\left(0.33 \sqrt{ } f_{c}^{\prime} \mathrm{MPa}\right)$, retained $80 \%$ of its capacity to $2.5 \%$ drift under average base shear stress demands as high as $7.4 \sqrt{ } f_{c}^{\prime}$ psi $\left(0.61 \sqrt{ } f_{c}^{\prime} \mathrm{MPa}\right)$.

- Shear distortions exceeding $0.01 \mathrm{rad}$ were calculated throughout most of the lower half of the first story of each wall in both specimens. Shear distortions were approximately twice as large in the compression wall as in the tension wall despite the higher expected shear stiffness. 
- The bases of the HPFRC walls exhibited higher curvature than the $\mathrm{RC}$ walls due to a greater concentration of deformations near the foundation. Peak curvature ductilities of 10 and 20 were calculated in the RC and HPFRC walls, respectively.

- Maximum compressive strains within $3 l_{w} / 8$ of the foundation were calculated to be as large as -0.012 approximately twice as large in the flanges as in the wall stems. Calculated axial tensile strains (as large as 0.056) were larger in the stem boundary region of the compression wall than in the flange of the tension wall throughout both tests. Both compressive and tensile strains were larger in the HPFRC walls due to concentration of rotations near the foundation.

- $\quad$ System geometry caused coupling beam chord rotations to exceed interstory drift by a factor of approximately 3 -close to the ratio of the distance between wall neutral axes at nominal strength to coupling beam length. Peak chord rotations of $4.5 \%$ and $10 \%$ were calculated at system drifts of $1.5 \%$ and $3.5 \%$, respectively.

\section{AUTHOR BIOS}

ACI member Rémy D. Lequesne is an Assistant Professor of Civil, Environmental and Architectural Engineering at the University of Kansas, Lawrence, KS. He is Secretary of Joint ACI-ASCE Committee 408, Bond and Development of Steel Reinforcement, and a member of Joint ACI-ASCE Committee 352, Joints and Connections in Monolithic Concrete Structures, and ACI Subcommittee 318-J, Joints and Connections (Structural Concrete Building Code). His research interests include the behavior of reinforced concrete members and earthquake-resistant design.

Gustavo J. Parra-Montesinos, FACI, is the C.K. Wang Professor of Structural Engineering at the University of Wisconsin-Madison, Madison, WI. He is Chair of ACI Subcommittee 318-J, Joints and Connections, and a member of ACI Committee 318, Structural Concrete Building Code, and Joint ACI-ASCE Committees 335, Composite and Hybrid Structures, and 352, Joints and Connections in Monolithic Concrete Structures. His research interests include the behavior and design of reinforced concrete, fiber-reinforced concrete, and hybrid steel-concrete structures.

James K. Wight, FACI, is the F.E. Richart, Jr. Collegiate Professor of Civil and Environmental Engineering at the University of Michigan, Ann Arbor, MI. He is Past President of ACI, past Chair of ACI Committee 318, Structural Concrete Building Code, and a member of Joint ACI-ASCE Committees 352, Joints and Connections in Monolithic Concrete Structures, and 445, Shear and Torsion. His research interests include earthquake-resistant design of reinforced concrete structures.

\section{ACKNOWLEDGMENTS}

This project was funded by the National Science Foundation under Grant No. CMS 0530383 and Bekaert Corp. It was part of the NEES research program. Special thanks go to Erico Corp. for donations of materials used in construction of the specimens. The ideas and conclusions are those of the authors and do not necessarily represent the views of the sponsors.

\section{REFERENCES}

1. Shiu, K. N.; Barney, G. B.; Fiorato, A. E.; and Corley, W. G., "Reversing Load Tests of Reinforced Concrete Coupling Beams," Proceedings of the Central American Conference on Earthquake Engineering: Conferencia Centroamericana de Ingenieria Siemica, 1978, pp. 239-249.

2. Tassios, T. P.; Moretti, M.; and Bezas, A., "On the Behavior and Ductility of Reinforced Concrete Coupling Beams of Shear Walls," $A C I$ Structural Journal, V. 93, No. 6, Nov.-Dec. 1996, pp. 1-10.

3. Galano, L., and Vignoli, A., "Seismic Behavior of Short Coupling Beams with Different Reinforcement Layouts," ACI Structural Journal, V. 97 , No. 6, Nov.-Dec. 2000 , pp. $876-885$.

4. Harries, K. A.; Gong, B.; and Shahrooz, B. M., "Behavior and Design of Reinforced Concrete, Steel, and Steel-Concrete Coupling Beams," Earthquake Spectra, V. 16, No. 4, 2000, pp. 775-799. doi: 10.1193/1.1586139

5. Canbolat, B. A.; Parra-Montesinos, G. J.; and Wight, J. K., "Experimental Study on Seismic Behavior of High-Performance Fiber-Reinforced Cement Composite Coupling Beams," ACI Structural Journal, V. 102, No. 1, Jan.-Feb. 2005, pp. 159-166.

6. Parra-Montesinos, G. J., "High-Performance Fiber-Reinforced Cement Composites: An Alternative for Seismic Design of Structures," ACI Structural Journal, V. 102, No. 5, Sept.-Oct. 2005, pp. 668-675.

7. Parra-Montesinos, G. J.; Canbolat, B. A.; and Jeyaraman, G. R., "Relaxation of Confinement Reinforcement Requirements in Structural Walls through the Use of Fiber Reinforced Cement Composites," 8th National Conference of Earthquake Engineering, San Francisco, CA, 2016.

8. Parra-Montesinos, G. J., and Chompreda, P., "Deformation Capacity and Shear Strength of Fiber-Reinforced Cement Composite Flexural Members Subjected to Displacement Reversals," Journal of Structural Engineering, ASCE, V. 133, No. 3, 2007, pp. 421-431. doi: 10.1061/ (ASCE)0733-9445(2007)133:3(421)

9. Lequesne, R. D.; Parra-Montesinos, G. J.; and Wight, J. K., "Seismic Behavior and Detailing of High-Performance Fiber-Reinforced Concrete Coupling Beams and Coupled Wall Systems," Journal of Structural Engineering, ASCE, V. 139, 2012, pp. 1362-1370.

10. Dazio, A.; Buzzini, D.; and Trub, M., "Nonlinear Cyclic Behavior of Hybrid Fiber Concrete Structural Walls," Engineering Structures, V. 30, No. 11, 2008, pp. 3141-3150. doi: 10.1016/j.engstruct.2008.03.018

11. ACI Committee 318, "Building Code Requirements for Structural Concrete (ACI 318-08) and Commentary," American Concrete Institute, Farmington Hills, MI, 2008, 473 pp.

12. ASTM C1609/C1609M-05, "Standard Test Method for Flexural Performance of Fiber-Reinforced Concrete (Using Beam With Third-Point Loading)," ASTM International, West Conshohocken, PA, 2005, 8 pp.

13. Liao, W.-C.; Chao, S.-H.; Park, S.-Y.; and Naaman, A. E., "SelfConsolidating High-Performance Fiber-Reinforced Concrete (SCHPFRC)Preliminary Investigation," Report No. UMCEE 06-02, 2006, 76 pp.

14. Lequesne, R. D., "Behavior and Design of High-Performance Fiber-Reinforced Concrete Coupling Beams and Coupled-Wall Systems," $\mathrm{PhD}$ dissertation, University of Michigan, Ann Arbor, MI, 2011, 277 pp. 


\section{aci in Your

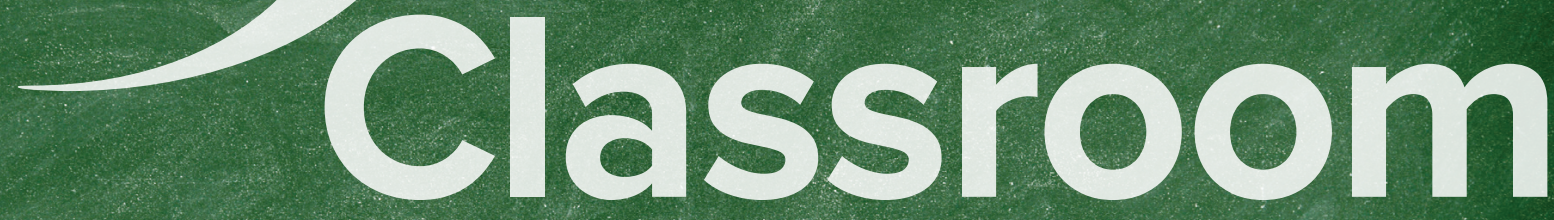

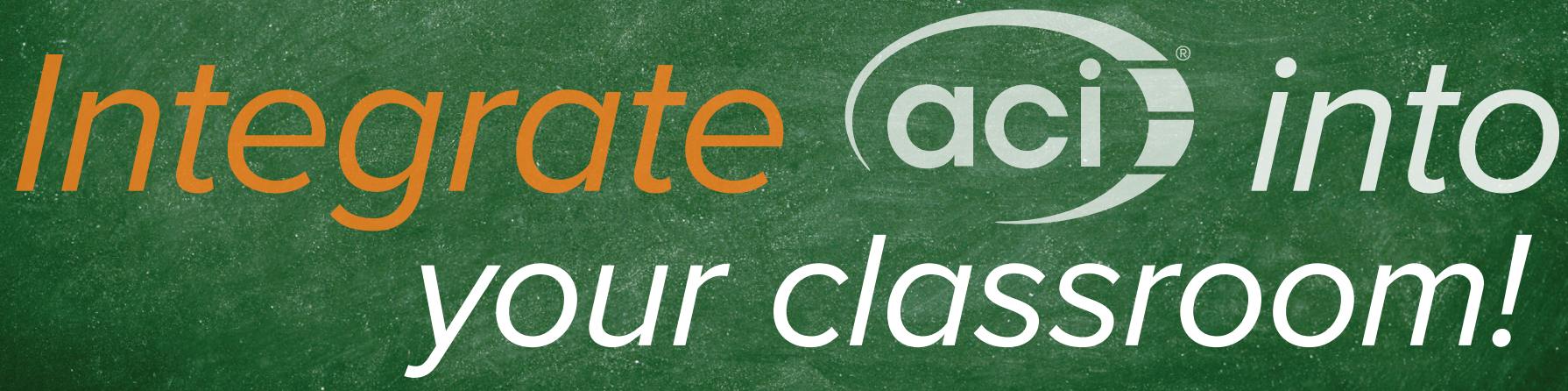

To support future leaders, $\mathrm{ACl}$ has launched several initiatives to engage students in the Institute's activities and programs - select programs that may be of interest to Educators are:

- Free student membership - encourage students to sign up

- Special student discounts on ACl 318 Building Code Requirements for Structural Concrete, ACI 530 Building Code Requirements and Specification for Masonry

Structure, \& Formwork for Concrete manual.

- Access to Concrete International - free to all $\mathrm{ACl}$ student members

- Access to ACI Structural Journal and ACI Materials Journal - free to all $\mathrm{ACl}$ student members

- Free sustainability resources - free copies of Sustainable Concrete Guides provided to universities for use in the classroom

- Student competitions - participate in ACl's written and/or team-based competitions
- Scholarships and fellowships - students who win awards are provided up to $\$ 10,000$ and may be offered internships and paid travel to attend ACl's conventions

- $\mathrm{ACl}$ Award for University Student Activities receive local and international recognition for your University's participation in concrete related activities

- Free access to ACI Manual of Concrete Practice - in conjunction with ACl's chapters, students are provided free access to the online ACI Manual of Concrete Practice

- ACl online recorded web sessions and continuing education programs - online learning tools ideal for use as quizzes or in-class study material 